\title{
SIETE NOVELAS DE BLEST GANA: UNA VISIÓN DE CONJUNTO ${ }^{1}$
}

\author{
Laura Janina Hosiasson \\ Universidad de São Paulo, São Paulo, Brasil \\ lhosiass@uol.com.br
}

\section{RESUMEN / ABSTRACT}

Lo que me propongo aquí es darle continuidad a una hipótesis ya anteriormente formulada por algunos lectores de Blest Gana. Se trata de la necesidad de un estudio capaz de relacionar toda la producción con los libros consagrados, en una integración de la obra como un todo, de manera orgánica, dentro de una visión general. En este caso, tomo las siete novelas que el autor publicó entre 1860 y 1864 para mostrar algunas de las redes que es posible establecer entre ellas.

Palabras Clave: novela chilena, literatura del siglo XIX, Alberto Blest Gana, realismo literario.

\section{SeVen Novels by Blest Gana: A VIEW of the Work as a Whole}

My purpose is to give continuity to an argument previously suggested by some readers of Blest Gana. The general idea is associated with the need of a study capable of establishing a link between all of the renowned books, as a way of integrating them in the work as a whole in an organic way and with a general vision. In this case, I take the seven novels which the author published between 1860 and 1864 to show some of the relationships that can be established between them.

KEYWORDS: Chilean Novel, Nineteenth-Century Literature, Alberto Blest Gana, Literary Realism. Recepción: 01/05/2017 Aprobación: 28/07/2017

1 Este ensayo forma parte de un proyecto más amplio en elaboración, en el que me detengo en el análisis de las crónicas y donde pretendo abarcar toda la producción del escritor. 
Pienso que en función de la lectura que propongo en este ensayo se puede considerar la obra en dos grandes tiempos. El primero abarca su labor como novelista, pero también como cronista y dramaturgo (publicó una pieza de teatro), entre 1853 y 1864, año a partir del cual el escritor se silenciaría por casi treinta años, cediéndole lugar al diplomático que pasaría a residir desde entonces en el extranjero. El segundo periodo va desde 1897, cuando al jubilarse del Servicio de Relaciones Exteriores, retomaría su pluma en París, donde publicaría otras cuatro novelas hasta 1912.

En los cinco años que median entre 1860 a 1864, dentro de lo que podríamos llamar los años finales del primer momento, Blest Gana dejó de escribir crónicas y se dedicó intensamente a la composición de siete novelas de extensiones variadas: La aritmética en el amor (1860), El pago de las deudas (1861), La venganza (1862), Mariluán (1862), Martín Rivas (1862), El ideal de un calavera (1863) y La flor de la higuera (1864). No pretendo entrar directamente en las razones de naturaleza diversa, en parte ideológica que provocaron la reiterada reducción a La aritmética en el amor, Martín Rivas y El ideal de un calavera, que configuraron la gran trilogía blestganiana de esa fase ${ }^{2}$. Lo que quiero es mostrar cómo en el recorte aquí propuesto, las siete novelas generadas en un periodo de enorme actividad productiva adquieren mayor envergadura, apreciadas en su conjunto. Al ser leídas de manera transversal, se advierte con más fuerza el impulso balzaquiano que las anima y del cual también se alejan, dibujando una modulación paradójica que deja ver la unidad subterránea más compleja y desafiante que las nortea.

Asimismo, gracias a esa mirada, es posible examinar de modo más sistemático las matrices románticas que presentan un vínculo problemático y contradictorio con la intención realista del novelista chileno.

Lo que me propongo aquí es darle continuidad a un punto de vista ya anteriormente sugerido por algunos lectores que se dieron cuenta de la necesidad de un estudio capaz de relacionar toda la producción, incluidas las crónicas y las novelas de los años iniciales, con los libros consagrados, en una integración de la obra como un todo, de manera orgánica, en una visión general. Conviene, en este sentido, registrar las palabras de Jorge Román-

\footnotetext{
De seguro, el primer premio nacional de literatura idealizado por José Victorino Lastarria y Manuel Amunátegui, adjudicado a La aritmética en 1861, así como el tono general edificante de Martín Rivas y los minuciosos cuadros de costumbres en El ideal, contribuyeron en esa preferencia.
} 
Lagunas, autor de la última bibliografía blestganiana general, ya que ellas traducen, en líneas generales, la propuesta de lo que pretendo desarrollar en esta oportunidad:

La casi totalidad de la crítica ha enfocado no más de cinco de las diecisiete novelas que Blest Gana publicó. Las obras anteriores a $L a$ Aritmética en el amor se señalan como tanteos o esbozos de novela, y en ésta se ve el inicio del género en Chile y el punto de partida de la serie novelística del autor. Las otras cuatro que cuentan ya con un aparato crítico apreciable son Martín Rivas, Durante la Reconquista, El loco Estero y El ideal de un calavera, en ese orden. De las doce restantes, hay relativamente pocas reediciones disponibles y hay ciertas novelas, como Juan de Aria, que son casi totalmente desconocidas. Resulta evidente que muchos de los autores de estudios de conjunto sobre el novelista las han dejado de lado, contentándose con repetir los juicios de Silva Castro, Díaz Arrieta o Amunategui Solar. Una revisión efectiva de estas obras -y con métodos vigentes- podría resultar del mayor provecho (607).

A pesar de algunas imprecisiones, como la de que Blest Gana habría publicado diecisiete novelas -sabemos hoy que fueron dieciocho-, pienso que la situación descrita por Román-Lagunas en su estudio de 1980 sigue presentando las mismas carencias en la actualidad. Se hace necesario leer y releer la obra entera, incorporar las novelas que, en función de criterios de índole variada, fueron siendo sistemáticamente descartadas del podio consagrado.

Más allá de lo que pueden sugerir los contenidos críticos expuestos de modo bastante sucinto por el escritor en sus únicos dos ensayos programáticos, De los trabajos (1859) y La literatura chilena (1861), creo que a esta altura es posible encontrar una matriz común para el conjunto, leído en su totalidad, a partir de la articulación de sus partes, pensando cada novela como componente de un proyecto mayor. Desde esta perspectiva, surge en el horizonte una trama básica fundamental oriunda de un proyecto común que va moldeándose a cada paso, expuesto a cambios y organizado a partir de diversas posibilidades de ejecución formal según el punto de vista que va siendo adoptado.

Las divisiones de la vasta producción en dos o en tres periodos, propuestas por algunos críticos (Alone, Silva Castro, Concha, entre otros) obedecen a juicios estéticos de variada índole y a un criterio cronológico que resulta de poca ayuda para la comprensión de lo que podríamos tratar de delinear como una poética. Guillermo Araya también notó una continuidad dentro de las 
opciones estéticas de Blest Gana, a pesar del "receso" de treinta años. Sin embargo, como el resto, atribuye pesos y medidas de valor, repitiendo el lugar común según el cual se destacan unas cinco o seis novelas y se descartan todas las demás por "menos valiosas o mediocres" (Araya, "Historia" 33).

El todo y las partes de la obra poseen una evidente identidad literaria. Prácticamente en todas las narrativas nos encontramos con altos y bajos, con tensiones y distensiones que dejan traslucir, a veces, los descaminos de una composición irregular pero que aun así es de una consistencia admirable que nos representa incluso en sus titubeos, defectos y aciertos más persistentes, a lo largo de un periodo decisivo de la formación histórica de Chile como nación moderna. En su interior respira el punto de vista particular del letrado Blest Gana sobre la herencia cultural chilena en sus primeros tiempos, sus usos, costumbres, modos de ser y de vivir en el campo, en la ciudad, dentro de todas las esferas de la vida social. Ese manantial de temas y motivos de la vida chilena del siglo XIX brota a lo largo de las dieciocho novelas. Tanto es así que cada crítico ha escogido sus "mejores novelas": Para Alone, los criterios variaron, puesto que en 1940 consideraba que Durante la reconquista era, "sin disputa, la obra maestra" (Alone, Don Alberto 140) y treinta años después resultaba que El loco Estero podía ser "acaso lo mejor que produjo como gracia y viveza tan típicamente chilena" (Alone, Crítica 1). Para Silva Castro, en 1934, Durante la Reconquista era "su mejor novela" (Silva Castro, "Durante" 5-52), pero ya en 1955 había cambiado de opinión y colocaba “...sin vacilar en primer término, El loco Estero, la más característica de todas ellas" y dejaba en cuarto lugar a Martín Rivas (Silva Castro, Alberto 336). Para Poblete Varas ${ }^{3}$, Guillermo Araya ${ }^{4}$ y Jaime Concha 5 , la selección será otra, distinta de las anteriores y apoyada en criterios bastante lábiles.

\footnotetext{
“Abelardo Manríquez es el personaje mejor dibujado" (152); "Las mejores novelas de su primera época: La artitmética en el amor, Martín Rivas y El ideal de un calavera (102).

"...sus novelas importantes o valiosas son seis: La aritmética en el amor, Martín Rivas, El ideal de un calavera, Durante la reconquista, Los trasplantados y El loco Estero" (Araya, "Historia" 33).

"la que más me encantó y me sigue pareciendo inolvidable (la releo a menudo) es El Ideal de un Calavera. ¿Por qué? No lo sé en absoluto. Tal vez mi debilidad por esa obra derive de la muerte y ejecución de Portales que allí conocí por primera vez, y que dejaba una mancha sangrienta en el origen de nuestro destino histórico como país". Palabras en la Universidad Alberto Hurtado el 11 de abril de 2012, por ocasión del lanzamiento de su libro Leer a contraluz. En www.letrasenlinea.cl.
} 
Con el pasar del tiempo y con la distancia que nos separa de las circunstancias en que el autor concibió su labor, fueron perdiendo fuerza la función formadora de la literatura, la misión del escritor nacional, el interés por lo local, la valorización de lo pintoresco y la caracterización de una especificidad chilena. En su lugar, otros aspectos han adquirido relevancia como, por ejemplo, lo que podríamos denominar un "sistema interno" de funcionamiento de esa narrativa que, a su vez, nos remite directamente a una visión abarcadora del Chile del siglo XIX. El modelo balzaquiano de una obra total cobra aquí aún más importancia para una lectura en perspectiva. En este sentido, es también muy significativo el camino que ha realizado Jaime Concha. Desde los años setenta hasta su libro de 2011, pasando por el prólogo de la edición Ayacucho, de 1977, su interés se centró en la lectura de Martín Rivas. Pero en ensayo reciente, afirma que "Blest Gana merece que se lo conozca mejor y que se exploren los repliegues de su obra que no calzan con la imagen más bien fija y convencional que de él se tiene" (Concha, Identidad 3). En el mencionado artículo irá a dejar de lado las más revisadas, Martín Rivas y Durante la reconquista, para dedicarse con mayor cuidado a una de las primeras novelas, El primer amor, de 1858 y a El ideal de un calavera, de 1863.

La cuestión es que, al tomar la obra desde esta perspectiva, es posible observar hasta qué punto el novelista experimentaba formalmente como su modelo francés, Balzac, al adoptar variantes con relación a la factura, a los puntos de vista, a la posición de los narradores, al cambiar significativamente la relación de cada uno de ellos con la trama general. En efecto, a partir de la primera novela se van a ir alternando en la configuración del universo ficcional los diferentes tipos de narradores (narrador protagonista, narrador testigo, narrador omnisciente intruso, narradores más o menos neutros, en tercera persona, con incursiones en el discurso indirecto libre), combinados con el uso frecuente de narraciones enmarcadas. Esos ensayos formales iban mucho en dirección a aquello que también había seducido a Balzac: el vaivén sobre las mismas obsesiones, el retorno a los mismo temas y tipos humanos, adoptando diferentes perspectivas. Experimentaba, por ejemplo, con las posibilidades estructurantes de la novela epistolar tan en boga desde el siglo XVIII. Un drama en el campo, de 1859, abre y cierra con una carta; la fórmula aparecerá también en Martín Rivas, de 1862, con algunos matices y variantes; El pago de las deudas, de 1861, avanza durante varios capítulos mediante un intercambio epistolar que propicia la rica alternancia de puntos de vista. En El ideal de un calavera, de 1863, el procedimiento va a servir, 
entre otras cosas, para caracterizar jocosamente los escollos ortográficos de Inés Arboleda, la musa romántica del protagonista. Vale la pena verificar el modo como es retratada aquí, con delicada ironía, la situación de las mujeres en la sociedad patriarcal decimonónica que -salvo en contadas excepcionesrozaban el completo analfabetismo ${ }^{6}$ :

Como las personas de su sexo en general, la hermosa joven temía más descubrir su falta de cultura en una carta mal escrita, que el compromiso que esa carta podría originar a su buena reputación. Muchos amantes han maldecido el recato de una querida, sin figurarse que sus verdaderos enemigos han sido las reglas de ortografía. Inés, empero, tenía la decisión de las coquetas que prefieren dar un paso aventurado a perder un adorador interesante. Esta fuerza de voluntad le sugirió la idea de vencer los escollos ortográficos a costa de paciencia, y con tal fin decidió no emplear, en caso de duda, más que palabras sacadas de algún libro (Blest Gana, El ideal 131).

Ya ha sido dicho que uno de los ejes temáticos de esta producción es el amor. Alone lo explicitó con todas sus palabras: "ninguna otra cuerda de su registro vibra con tan persistente y vigorosa insistencia" (Alone, Don Alberto 239). De hecho, Doris Sommer se basa en esa premisa para realizar su provechosa lectura alegórica de Martín Rivas ((204-220). Sucede que una mirada más amplia sobre sus novelas permite verificar la omnipresencia de la aventura amorosa contrapuesta casi siempre a una dinámica adversa: la del dinero, y la forma como ese conflicto principal se resuelve en cada oportunidad va a depender de los diferentes protagonistas. Algunos se dejan seducir por el brillo fatuo del vil metal, como Fortunato Esperanzano de La Aritmética en el amor; otros se mantienen refractarios, como Abelardo Manríquez de $E l$ ideal de un calavera, o arrepentidos, como Luciano de El pago de las deudas. Las soluciones pueden variar desde el final feliz a la tragedia, pero la tónica del dinero -la más evidente del realismo- es la que veremos repitiéndose a lo largo de toda la producción, desde Una escena social (1853) hasta Gladys Fairfield (1912). El desenlace, sabemos, no es un detalle menor y justamente con él me parece posible abrir una puerta decisiva para la comprensión del heterogéneo conjunto y de los modos de recepción de la obra.

6 Es necesario destacar que el escritor se había manifestado en favor de la educación para las mujeres en una crónica de 1859, titulada "Contrastes: lo de antes y lo de ahora": 178. 
Si tomamos las siete novelas publicadas entre 1860 y 1864 , constataremos la impresionante variedad de soluciones compositivas, lograda a partir de un núcleo temático similar. Vale registrar que, salvo La aritmética en el amor y Martín Rivas, las demás cinco novelas se encaminan hacia finales trágicos. En este sentido, no deja de ser significativo que la primera de las dos haya recibido el primer premio de literatura de la Universidad de Chile, en 1861 y que la segunda se haya transformado en la novela chilena más emblemática de todo el siglo XIX, y la más reeditada y traducida a otros idiomas. El destino menor de las otras cinco tampoco fue uniforme, tres de ellas fueron completamente olvidadas: El pago de las deudas (1861), La venganza (1862) y La flor de la higuera (1864). Ya El ideal de un calavera (1863) ha merecido algunas reediciones y cierta atención de la crítica (Gotschlich y Poblete Varas) y, por fin, Mariluán (1862) ha salido de su casi absoluto ostracismo gracias al interés reciente y creciente de los estudios culturales ${ }^{7}$.

Es decir que de un lado tenemos dos novelas solares con dos jóvenes arribistas sociales, Fortunato y Martín (este último más escrupuloso que el primero), ambos con una trayectoria victoriosa que les propiciará la adquisición de una excelente posición económico-social y el matrimonio con la mujer amada. Ya del otro lado, se nos presenta un abanico más complejo de cinco protagonistas cuyos caminos conducen irremediablemente hacia un final trágico. Entre ellos también encontramos al arribista social que busca resolver sus problemas pecuniarios a través de un matrimonio adecuado. Pero aquí (en El pago de las deudas) Luciano no tendrá la suerte y el buen tino de Martín ni la absoluta y pueril falta de consciencia moral que caracteriza a Fortunato Esperanzano. Luciano es un calavera que se debate sin tregua con los remordimientos por sus actos impensados y anti-éticos. Mientras Fortunato se deja asesorar por Anastasio Bermúdez, el amigo inescrupuloso -en una relación muy similar a la del pérfido Vautrin con su discípulo Rastignac en Le père Goriot-, el pobre Luciano deberá enfrentarse a los antagonismos morales de su mundo interior:

Habia abandonado a su mujer rompiendo los sagrados vínculos que a ella le unian, i destrozado, acaso para siempre, un corazón al que solo debía amor i reconocimiento. Habia pisoteado sus deberes, despreciado el fallo social, acallado su gratitud i destruido la paz de

\footnotetext{
Destaco los estudios pioneros de John Ballard (1981), así como los de Amado Lascar (2003) y de Gilberto Triviños (2004).
} 
dos familias, vencido por un amor culpable i con la única esperanza de que ese amor sofocaría la voz de sus remordimientos (sic). (Blest Gana, El pago 244).

En 1862 surgen tres personajes completamente diferentes entre ellos: la peruana vengadora Juana Mendoza (única mujer protagonista en Blest Gana), el irreprensible Martín Rivas y el heroico araucano Fermín Mariluán. El hecho de que el joven novelista chileno publicara tres historias de naturaleza tan distinta en un mismo año torna manifiesto el movimiento de búsqueda, de impulso ensayístico que mencionábamos antes. Los subtítulos que las tres novelas ostentaban en un primer momento, al ser publicadas como folletines en el diario La voz de Chile, evidencian ese deseo de experimentación: la primera se llamó La venganza: tradición limeña; la segunda, Martín Rivas, llevó el subtítulo novela de costumbres político-sociales hasta la edición de 1925; y la tercera apareció como Mariluán: crónica contemporánea. Esos subtítulos que fueron suprimidos seguramente por criterios editoriales posteriores a la muerte del escritor pueden ser leídos como las tesis que sostienen cada uno de los tres proyectos.

En realidad, este pequeño núcleo de tres novelas contemporáneas, publicadas el mismo año, representa un ejemplo perfecto de lo que defiendo con relación a la pertinencia de esta lectura. En vez de reducir la producción de 1862 a Martín Rivas, esa aproximación con las otras dos novelitas (el diminutivo lo utilizo en referencia al tamaño) permite examinar la reaparición y reelaboración de temas y de tipos. También es posible comprender así la forma como novelas muy diferentes se complementan entre ellas y de qué modo sus puntos de vista, procedimientos y desarrollos narrativos funcionan como contrapuntos entre unas y otras. Así se abren posibilidades de comprensión de un universo narrativo más complejo, contradictorio, ambiguo y de ningún modo homogéneo.

Aunque sea cual sea el tratamiento y las direcciones que el argumento adopte, la tensión entre las relaciones amorosas y los intereses económicos está siempre en situación central; por otro lado, los protagonistas, así como los ambientes, situaciones y momentos históricos son muy diferentes, lo cual propicia andamientos y desenlaces específicos en cada realización.

La venganza que salió a la luz en marzo de 1862 está ambientada en el siglo XVIII, en una Lima colonial y narrada mediante el uso de un vocabulario y formas del español peninsular que buscan aproximarse a la capital del virreino. Es un relato breve, una novela corta que explora dentro de ese 
contexto el motivo romántico de la belle dame sans merci (Praz 347-516) encarnado en la protagonista, la bella criolla Juana Mendoza, mujer fuerte, independiente y decidida, en nada parecida al extenso elenco de personajes femeninos que pueblan las novelas anteriores y las de este período. A su altura estará solamente Luisa Bustos, veinte y siete años más tarde, en Durante la Reconquista. Pero Juana Mendoza, desde un ángulo más personal, es aún más intrépida y temeraria: abandona al padre tras el amor de un hombre que poco después la va a abandonar a su propia suerte por un matrimonio de conveniencia. La narración se desarrolla dentro de una atmósfera de rasgos góticos, reforzada por el tema de la mujer fatal que, por venganza, asesina a sus pretendientes:

-¿Y quién es ella? -preguntó éste.

-Una mujer rodeada de un profundo misterio -dijo uno.

-Que nadie se atreve a visitar -añadió otro.

-Vive Dios, señores -exclamó él marques-, que me place cuanto estoy escuchando. ¿Y por qué tal misterio? ¿Y por qué no se atreve nadie a visitarla?

-Corren extrañas voces sobre Juana -contestó un joven, a quien el marqués había dirigido su vista mientras hacía las preguntas anteriores. -¿Y qué dicen esas voces?

Los jóvenes se acercaron al centro que ocupaba el marqués, y uno de ellos le dirigió la palabra; pero no como antes en voz alta, sino en tono confidencial y misterioso.

-En Lima no ha habido más que dos hombres -dijo- que hayan manifestado públicamente su pasión a Juana y en el espacio de pocos meses los dos han desaparecido.

-¡Bah, será bruja! -exclamó riéndose el marqués.

-Bruja o no -repuso el otro muy serio-, lo cierto es que esos dos jóvenes, que perseguían con amores a Juana, han desaparecido de Lima, y todas las pesquisas de sus familias para descubrirles han sido inútiles hasta hoy (Blest Gana, La Venganza 5-6).

No es posible dejar de notar a estas alturas que no hay nada aquí de compromiso con una literatura nacional, por lo menos en los términos en que el autor lo había descrito un año antes, en su discurso programático de 1861. ¿Lapsus del novelista? Me parece que no, si prestamos atención a la expansión del interés de este realista decimonónico por contextos que alargan las fronteras hacia un tejido más complejo sobre el cual se iría forjando lo nacional. En 
este sentido, no sería tampoco aleatorio afirmar que tanto esta pequeña narrativa como después el caudaloso Durante la Reconquista, articulan pares románticos entre españoles e hispanoamericanos que irán definiendo las diferencias entre ambos. La relación amorosa aparece aquí formulada como símbolo del enfrentamiento histórico entre dos épocas y dos culturas, lo que ayuda a contrastar el decadentismo español con el ímpetu idealista, liberal y revolucionario de los hispanoamericanos, según la visión romántica.

La segunda novela de 1862, Martín Rivas, lo consagraría como el gran escritor del siglo XIX chileno, ofuscando desde su primera aparición todo el resto de la producción ${ }^{8}$. Es verdad que las expectativas del público lector tuvieron mucho que ver con el estrepitoso triunfo, como ya lo señaló Juan Poblete. Martín Rivas cuyos capítulos fueron apareciendo entre mayo y julio de ese año, llegaba para transformar en materia literaria a la "naciente modernidad urbana chilena" (44), otorgándole visibilidad al mismo nivel de los asuntos europeos. Este público lector estaba compuesto en su gran mayoría por los mismos letrados que aplaudían el libro en el cual se veían reflejados como en un espejo. Por otro lado, en esa predilección entra en juego un factor determinante no menos significativo y en esto también se separa de sus hermanas gemelas, las dos otras novelas de ese año: Martín Rivas y su ideario liberal-conservador representa una visión solar de los destinos de la burguesía chilena. Aunque a partir de un ángulo bastante irónico y distanciado, representa la fórmula político social que podría dar resultados positivos. Las tres décadas de gobiernos liberales estaban comenzando en 1861, con la elección de José Joaquín Pérez, y el final feliz de la novela funcionaba como confirmación de la ecuación ideológica que la alentaba. Esta es la lectura que propone Doris Sommer. El joven protagonista criollo, aspirante a abogado, recién llegado de la provincia a la capital, va a conquistar tras no pocas vicisitudes, su lugar al sol en el seno de la burguesía adinerada de Santiago, al lado de la bella heredera de la familia Encina. Ya hemos visto en otro lugar (Hosiasson, "Contradicciones" 240-245) que esa trayectoria implica un sentido circular al religar el capital producido en el campo con su ostentación en la ciudad. Se trata aquí de la recuperación de una posición de derecho

\footnotetext{
El éxito inmediato de la novela queda consignado en carta de ese año, en la que él mismo anotaba: “...Martín Rivas. Sensación en el público, coro de felicitaciones, artículos lisonjeros, quejas de mujeres cuando se interrumpe su publicación, cartas de elogios, todo llueve sobre el autor como una lluvia de flores" (Blest Gana, Epistolario 1, 28).
} 
adquirido. Por otro lado, releyendo la novela dentro de la perspectiva aquí propuesta, Martín podría ser considerado como la versión más seria y más responsable de Fortunato y de Luciano, los protagonistas de La aritmética en el amor y El pago de las deudas. Las tres novelas parecen formular la misma pregunta balzaquiana sobre cómo se triunfa en la ciudad grande, a la cual responden al unísono: "lo que tú debes procurar es darte a conocer, frecuentar la alta sociedad, donde encontrarás poderosas protecciones.", (Blest Gana, La aritmética 106) En cada una de ellas, el esquema encuentra soluciones diferentes, pero se trata evidentemente de algo que Blest Gana venía trabajando a partir de sus primeras publicaciones ${ }^{9}$ y cuya persistencia resulta ser más fuerte que la de la función nacional, cuando consideramos el espectro general de la obra, desde una perspectiva actual. Con o sin color local, con o sin episodios de la historia nacional, la cuestión del dinero mantiene siempre su primacía en el esquema realista, lo cual hace gravitar en su órbita al motivo amoroso. El amor pobre no tiene futuro en ningún contexto. La observación de Roberto Schwarz cuando lee "Le père Goriot" sirve aquí como guante: "las señales de pobreza son una ignominia, un fracaso en el mundo moderno y capitalista" (172). Lo que aterroriza a todo el elenco de personajes, es la perspectiva de caer en la pobreza o de no lograr salir de ella. Su novela Los desposados, publicada en 1855 y ambientada en la París de las barricadas de 1848, ya ensayaba posibilidades trágicas y patéticas de esa constatación que iría sedimentándose a lo largo de los años, en sus demás producciones.

Nada más lejano de Martín Rivas que el destino que tuvo Mariluán, otra de las novelas olvidadas, como la llamó John Ballard (2-9). Fue publicada algunos meses después (entre octubre y noviembre) y ambientada en 1833, en Los Ángeles, ciudad austral en la región de la frontera con la nación mapuche. La narrativa abre estableciendo un linaje explícito con La Araucana, de donde va a extraer las virtudes del protagonista, Fermín Mariluán, hijo de un cacique y educado entre blancos:

La indómita energía de la raza inmortalizada por los cantos de Ercilla brillaba en los ojos de Fermín Mariluán. En un pecho espacioso y levantado, latía su altivo corazón, cuya viril entereza daba a sus negros

9 Lo encontramos también en torno a tres protagonistas de su producción de 1858: el poeta Fernando Reinoso de El primer Amor; en Camilo Ventours, de La fascinación; y en Enrique Saldalla, de El jefe de la familia (única pieza de teatro blestganiana). 
y pequeños ojos su tranquilo mirar, y a los labios, algo abultados, la fría expresión de orgullo que caracteriza la fisonomía de los araucanos (Blest Gana, Mariluán 1).

Las virtudes del indio mítico en el poema de Ercilla se encarnan en el civilizado Fermín, mientras que sus rasgos demoníacos y bárbaros se incorporan en el feroz Peuquilén:

...Peuquilén se había hecho notar por su temeraria osadía: los rasgos de crueldad que le hacían notable en la guerra, lejos de desacreditarle a los ojos de los indios, le revestían de cierto prestigio, que aumenta entre los salvajes el valimiento en razón de los abusos que de la fuerza bruta es capaz de cometer un hombre (Blest Gana, Mariluán 36).

Esa ambivalencia en la entrega de la imagen del indio no se da solamente en el plano de esos dos personajes contrapuestos; se encuentra también en la cisión del narrador que oscila desde el enaltecimiento de la raza araucana a la constatación de su intrínseca e indomable barbarie. Tanto es así que Gilberto Triviños pudo constatar en su lúcida, aunque un tanto alucinada lectura aquello que definió como la crítica de tradición moderna sobre Mariluán, que ha sido prácticamente unánime en consignar el carácter ambiguo y contradictorio de su argumento (33-57).

John Ballard llega a afirmar que Mariluán sería mejor que Martín Rivas, por la ejecución más condensada del argumento y por la incorporación de un tema tan pungente como el de los mapuches y su complejo y violento proceso de integración al Estado nacional. Sin ir necesariamente tan lejos, la cuestión es que al considerar que ese mismo año y en el mismo diario La Voz de Chile, el escritor publicaba además la novelita peruano-colonial, se hace necesario raciocinar en términos de una tríade de 1862 , y no de un binomio. Eso significa evaluar conjuntamente las tres. Con relación a la totalidad, significa pensar en una poética general del autor que va mucho más allá de la tentativa de empeñar su labor literaria en aquello que a la luz de los textos programáticos se entiende por novela comprometida de cuerpo y de alma en el proyecto afirmativo de la construcción nacional. Hay más que eso en esta producción.

Sin adentrarnos en el pormenor de estas cuestiones, podemos pensar en una voluntad integradora más allá de las fronteras nacionales, en una intención proyectiva de su literatura dentro de un ámbito más vasto, en términos 
regionales y no estrictamente nacionales ${ }^{10}$. Prueba de esa voluntad serían sus propias palabras: "Busco lectores y aspiro a que mis novelas salven los límites de la patria y hagan conocer mi nombre en el resto de la América" (Blest Gana, Epistolario 134 ). En su primera edición, La venganza estaba dedicada al amigo y pintor peruano Federico Torrico (1830-1879), a quien atribuye la autoría del argumento. Los primeros párrafos de esta novela corta se abren con la visión de una procesión de Corpus Christi alrededor de la Plaza Mayor de Lima en que el narrador hace un aparte para resaltar que los vecinos del norte son "el único pueblo de la América Española que ha conservado hasta el día costumbres originales" (Blest Gana, La venganza 5). Aquí es necesario entender que, hacia 1862, la guerra contra la Confederación Perú-Boliviana, de 1832, era un pasado medianamente superado y que la Guerra del Pacífico (1879-1883) no estaba aún en el horizonte de lo probable. Las cosas iban a cambiar entre chilenos y peruanos. De hecho, consta que hasta poco antes de su muerte, en 1879 y en vísperas de la guerra, Federico Torrico -además de pintor, también periodista y político- dirigió trabajos de prospección para el abastecimiento de agua en una Iquique todavía peruana por aquellos tiempos... ${ }^{11}$

Si le añadimos a esta narrativa limeña sobre finales del siglo XVIII, una de los años treinta en las fronteras del mundo indígena y otra de mediados del siglo XIX sobre la ascensión burguesa en el mundo del capitalismo moderno santiaguino, tendremos un panorama embrionario de un proceso hispanoamericano. En Los trasplantados, de 1904, el narrador va a referirse a sus rastacueros en París no como a chilenos, sino como a "hispanoamericanos", lo que prueba que el drama del desarraigo cultural seguiría siendo para Blest Gana un problema de "el resto de la América". Según la lectura propuesta por Doris Sommer que, a mi modo de ver, es tan aguda como sintética y generalizadora, las tres novelas de 1862 podrían ser leídas como tres alegorías de la historia político-social hispanoamericana: La venganza, que muestra en clave romántica la trágica resistencia y decurrente sumisión criolla a España, durante la colonia; Martín Rivas, como la alegoría de una apuesta sobre la conflictiva conciliación de ideologías antagónicas, a mediados del siglo XIX;

10 En esta dirección trabaja Jaime Concha en su último ensayo "Identidad" (2016).

$11 \quad$ Ver Carlos Donoso Rojas, "El puesto de Iquique en tiempos de administración peruana”. Historia (Santiago) 36 (2003). 
y por fin, Mariluán, que representa la imposibilidad del amor interracial y de la convivencia armónica entre indios y blancos. No cabe duda de que el proyecto general crece según esta perspectiva.

$\mathrm{Al}$ año siguiente, en 1863, veremos aparecer El ideal de un calavera, con un protagonista inclasificable, capaz de descolocar al narrador y poner a prueba los esquemas sociales y económicos que rigen el mundo burgués a su alrededor. El propio autor llegó a definirlo como "un Werther que se habría reído de los escrúpulos de Carlota" (Blest Gana, Epistolario1 40). El romanticismo realista de esta novela es más rico que el de Martín Rivas, en cuanto a la presentación de escenarios diferentes: la vida social en la capital, la familia de la oligarquía rural, el rodeo, la fiesta campestre, el teatro popular, la noche de Navidad y sus pesebres se van alternando en torno a las peripecias de Abelardo Manríquez. Este protagonista vive preso de su idea fija, la obsesión quijotesca por la búsqueda del ideal amoroso, extraído de lecturas y de relecturas de la novela epistolar del siglo XII, Abelardo y Heloisa. Aquí la postura anti conservadora (anti pelucona) del novelista se torna más evidente que nunca. El desprecio del personaje y de sus amigos calaveras por los usos e impostaciones de la oligarquía, por las convenciones del matrimonio y de la iglesia, así como por las creencias populares se dejan ver junto a la labia mordaz con que el narrador hace alusión a la gestión de Diego Portales y a su asesinato:

Un hombre, a quien su propia audacia sirvió de escala para subir al poder, que hizo de su voluntad la ley de la República, que confundió con su incansable actividad a los que le rodeaban y que tuvo bastante talento para crearse admiradores entre los que trataba como a esclavos, es el que llena las páginas de la historia de esos años [...] resuena de un confín a otro de la República, desde los tiempos agitados en que el Liberalismo regó las márgenes del Lircay con la sangre de sus mejores hijos hasta la noche en que el Ministro omnipotente tuvo que arrodillarse para recibir la muerte... (Blest Gana, El ideal 586-587)

Todo ello contradice de manera frontal la idea generalizada que se hizo de Blest Gana como un escritor paradigmático de un tipo de novela nacional que celebraría alegóricamente la historia eufórica del liberalismo económico y político chileno.

Una lectura de Martín Rivas en esos términos se torna por lo menos cuestionable, como ya lo probó Jaime Concha (Concha, Prólogo) y como se puede apreciar también a partir de la revisión conjugada de otras novelas 
del período que, como El ideal de un calavera, muestran una actitud crítica y melancólica con respecto a ciertos episodios de esa misma historia nacional. Los rumbos del liberalismo hispanoamericano no fueron eufóricos, a no ser durante la primera década tras las Independencias. A continuación, fue perdiendo su fuerza y entre el discurso y la práctica se fue instalando un abismo. Contra la anarquía y la temida revuelta de las masas, cedió espacio a las necesarias alianzas con el conservadorismo y éstas fueron minando de a poco el ideario de libertad y de justicia social que había caracterizado al período fundador. La historia del liberalismo hispanoamericano es la de un ciclo desgastante e infausto, en el cual llegó a hacerse difícil "distinguir a un conservador liberal de un liberal conservador" 12 .

Nuestro escritor es receptivo a ese movimiento y da cuenta de esa complejidad por medio de herramientas del romanticismo idealista, por un lado, y del realismo, por otro, para penetrarla a través de sus varios niveles de significado: los hechos históricos, los retratos de grupos sociales, los tipos característicos románticos y pragmáticos y sus interrelaciones cruzadas por el engranaje del dinero que dicta el compás de cada movimiento.

En la última novela del periodo, La flor de la higuera, del año siguiente, tampoco encontramos motivos de celebración. A no ser por una adaptación al cine en un cortometraje de 2010 realizado por Daniel Rebolledo y Alonso Machuca, quedó olvidada y nunca volvió a ser publicada después de la segunda edición, en 1853. La brevísima y trágica historia de este Romeo y Julieta en suelo chileno, abre con un narrador personaje que dice estar terminando de escribir uno de los capítulos de Martín Rivas, lo cual lo remite, por un lado, a la práctica cervantina de los espejismos de la obra dentro de la obra, y por el otro, permite que el escritor sea, en el plano de la ficción, el depositario de la historia que un amigo le irá a transmitir sobre la pugna familiar que originó la tragedia: "Me estaba contando el curial, mi nuevo amigo, de cómo el cura y el gobernador, por desavenencias políticas, habrían fundado en el pueblo un odio aparecido al de los Montescos y Capuletos..." (Blest Gana, La flor 12). La figura del amigo, Marcos, a su vez trae consigo todas las marcas de otro personaje de apoyo, con el mismo nombre, que había figurado en El primer amor, de 1858, y que también había hecho una breve aparición en

12 Remito aquí a los trabajos de José Luis Romero (1981); de Beatriz González Stephan (1987) y de Roberto Gargarella (2005). 
La aritmética en el amor, de 1860, novela en la cual el motivo de las dos familias en pugna ya se encontraba esbozado:

\begin{abstract}
Allí se reproducía la eterna historia de Montescos y Capuletos, el odio de familia a familia [...] Una división perpetua de privados intereses, una guerra perenne de solapada maledicencia, míseros odios y míseras venganzas, he aquí las causas de la lucha y los medios de acción empleados por las familias Selgas y Ruiplán que componían la mayoría de la población y a las cuales se hallaban ligadas por estrecho o lejano parentesco las demás buenas familias de la ciudad (Blest Gana, La aritmética 180)
\end{abstract}

Esos juegos intertextuales nos dan una clara idea de que el escritor tenía perfecta conciencia sobre la dimensión total de su obra. Por otro lado, la alusión explícita en esta novelita a The bride of Lammermoor de Scott y la mención a los Montesco y a los Capuleto shakespearianos se van a cruzar con una leyenda de origen mapuche sobre la flor de la higuera, narrada minuciosamente por uno de los personajes. Ambas atmósferas, la de las tradiciones literarias occidentales y la indígena, impregnan y pulsan en esta narrativa con una fuerza que no ha sido todavía evaluada.

En estas siete novelas entre 1860 y 1864 , a pesar de las obvias diferencias de tamaño, de abordaje y de argumento, es posible trazar un par de constantes. La primera, el peso del dinero en el armazón de las redes sociales y, en particular, su injerencia en el destino de los pares románticos y en la transformación del sexo femenino en mercadería. Como ya lo notamos antes, el matrimonio es un negocio y es necesario casarse bien, o sea con alguien con dinero. Dos de los títulos -La aritmética en el amor y El pago de las deudas-aluden directamente a esto. Aunque nunca se la mencione explícitamente, la sexualidad es un motivo omnipresente y está siempre en estrecha relación con ese nudo temático central. En todas las historias los personajes masculinos disponen de alternativas más o menos variadas para enfrentarse a la vida en sociedad y a sus destinos dentro de ella, dependiendo de si tienen o no posición económica. Es lógico que los ricos podrán pleitear más dividendos que los pobretones, pero ya vimos que incluso para Fortunato Esperanzano y para Martín Rivas - no agraciados por la fortuna de inicio-el asunto termina bien. En cambio, para las mujeres sin fortuna esas alternativas se reducen considerablemente a la administración más o menos inteligente de sus recursos: la juventud y la belleza en la oferta de sus sexos al mejor partido. El narrador será impiedoso con aquellas menos dotadas físicamente, 
a las cuales solo una fortuna familiar podrá salvar del tan temido celibato. Ese es el caso de doña Engracia Nuñez, la suegra de Martín Rivas quien, a falta de la gracia que lleva en su nombre (hay muchos toques como éste de ironía en los nombres de los personajes de Blest Gana), tenía una dote de 30.000 pesos con la cual conquistó el corazón de Dámaso Encina.

Por otra parte, los relatos marcan muy bien la diferencia entre mujeres sexualizadas que se encuentran de dos tipos, siempre en situación contrapuesta. El primer grupo, el de las "bien intencionadas", incluye a Rosa Tudela (Mariluán) y a Magdalena (La flor de la higuera), que someten sus purezas y castidades a la dura prueba de la fuga con el amado, antes de la aprobación de las nupcias. Se enfrentan así a la culpa y a los remordimientos, como quien se somete al sacrificio. Otra de ellas, Juana Mendoza (La venganza), tras la fuga con el amado, será abandonada por otra opción más ventajosa para él. Ella va a transferir entonces su odio a todo el género masculino e irá asesinando a sus seductores, uno tras otro. El segundo grupo es el de las "desfachatadas" que venden sus atractivos físicos al mejor postor, como Julia Valverde (La aritmética en el amor), Adelina (El pago de las deudas), Adelaida Molina (Martín Rivas) y Candelaria Basquiñuelas (El ideal de un calavera); pero su desfachatez será castigada por la pobreza o la degradación. En este sentido, la obra blestganiana se mueve dentro del espectro de posibilidades del realismo decimonónico ${ }^{13}$. Solo las jóvenes bellas y ricas podrán darse el lujo de escoger según sus deseos y caprichos, como es el caso de Margarita Mantoverde (La aritmética en el amor), Leonor Encina (Martín Rivas) e Inés Arboleda (El ideal de un calavera), cuyos apellidos botánicos podríamos pensar como alusiones a la frondosa protección de las fortunas paternas. En su ensayo "Blest Gana y el realismo", Ricardo Latcham consigna que el deseo de las figuras femeninas "no tenía otro horizonte que el amor legal o libre, marchitez de la soltería sin consuelo o el encapsulamiento del claustro" (118). Ya el acto sexual y el deseo erótico aparecen siempre sublimados. Con la única excepción del deseo del bárbaro Peuquilén por la joven Rosa Tudela que es puramente físico, aunque aquí, para describir el apetito de ese "león que, para refrescar su cabeza, agitaba la melena al aire y rugía, y con violenta impaciencia escarbaba el suelo que creía sentir inflamado porque su planta

13 El carácter conservador del realismo del siglo XIX ha sido ya ampliamente estudiado: Ver, entre otros, Harry Levin (1963); Leo Bersani (1975) y las varias lecturas de Luckács sobre el realismo. 
le comunicaba el calor", el narrador escrupuloso no se atreve a pronunciarlo y explicará que "apenas nos atrevemos a designar con el nombre de amor" (Blest Gana, Mariluán 72 y73).

Como ya lo observó Guillermo Araya, el amor en disputa, el triángulo amoroso, es de hecho una constante. El investigador chileno llegó a dibujar gráficos de cada una de las novelas para comprobar esa matriz composicional que organiza las tramas (Araya, "Alberto"186-187). En sí, eso ya era una novedad, ya que Araya fue el único crítico contemporáneo que mostró un panorama general, aunque se trate allí solamente de una ilustración hacia el final del ensayo, para probar su tesis de que la estética del triángulo reúne los temas del amor y del dinero en toda la producción. Araya dejó fuera dos novelas (La venganza y La flor de la higuera) porque para él no representaban el esquema triangular de las demás. En este sentido, convendría analizar la obra a partir de la teoría sobre el deseo mimético, expuesta por René Girard en su ya clásico libro Mentira romántica y verdad novelesca, de 1961. Ella permite verificar de qué modo se ponen en marcha los mecanismos del poder y del dinero inmiscuidos en todos los encuentros y desencuentros amorosos que salpican sus páginas. En La venganza, el novio abandona a Juana por otra mujer, más rica. Ese será el motivo propulsor de la trama. A través de la transformación de los demás hombres que la cortejan en "chivos expiatorios", ella intentará eliminar simbólicamente al "mediador interno", simultáneamente objeto y obstáculo para la realización de su deseo ${ }^{14}$.

La novela realista, según la ley de la restauración del orden, hará que el argumento se encamine en dirección a una anagnórisis, un reconocimiento de la perversión del esquema. Juana reconocerá al final la morbidez de su impulso destructor y asesino. Ya en La flor de la higuera, el triángulo mimético se torna más complejo porque involucra un litigio económico que opone a las familias de los amantes. Como entre los Montesco y los Capuleto del "teatro de la envidia" (Girard, Shakespeare), el deseo de poder y la ambición se cruzan con el deseo amoroso. Tenemos allí la triangulación motivada por el

14 Recapitulando groseramente los presupuestos de la teoría de Girard, todo deseo es mimético, es decir que está determinado por el deseo de otro, un mediador al cual se desea imitar. El caso emblemático de Don Quijote presenta un mediador (Amadís de Gaula), externo al mundo del protagonista, por lo tanto el deseo mimético de la caballería y de la conquista de la Dama no se enfrenta directamente al de su mediador. En este caso, en cambio, todos los elementos del triángulo están dentro de la trama interna, lo cual la encamina hacia el conflicto trágico. 
mediador interno del dinero (en este caso, un litigio limítrofe de propiedades contiguas) que transforma a los amantes en chivos expiatorios que deberán ser sacrificados como en la pieza de Shakespeare, para que ocurra la restauración de la paz entre los litigantes.

Solo para cerrar este aparte que merecería por cierto ser profundizado ${ }^{15}$, quiero volver al motivo del amor-deseo del temible Peuquilén, cuyo blanco es Rosa Tudela. Si admitimos con Girard que todo deseo es mimético y mediado, estamos de acuerdo en que adquirirá nuevos matices también en el caso del sentimiento de ese araucano feroz. Su atracción fatal y desmedida por la joven blanca está pautada por el estímulo de un modelo que quiere imitar: el de Fermín Mariluán, el indio civilizado. O sea que, por detrás del deseo del bárbaro indígena en esa novela, está el impulso mimético como un deseo de aculturación, parecido al del propio Fermín. Sucede que, en el contexto del siglo XIX, ese deseo era de realización imposible, así como también era imposible la concretización del sueño de paz y de justicia de Fermín. Como sugiere Gilberto Triviños, aquí residiría el valor utópico de la novela: en la formulación de un proyecto de equilibrio racial en medio de su completa imposibilidad de realización (12-18). Por otro lado, y pensando en una dimensión más amplia de esa teoría, la idea de la necesidad de recomponer el triángulo mimético para restaurar un orden se colocaría también en la relación de los intelectuales latinoamericanos que, a la manera de Blest Gana, imitaban a sus modelos europeos y norteamericanos, a lo largo del siglo XIX...

El segundo motivo recurrente en este grupo de siete novelas es la fiesta, la tertulia o la reunión social en donde se congregan los personajes antes o después de la deflagración de los conflictos, para articular los futuros desdoblamientos de los acontecimientos en juego. Aunque ya se ha dicho que la inclusión de las festividades se impone por el imperativo nacionalista de la descripción del suelo patrio, pienso que también es posible concederle al escritor una genuina preocupación por la ejecución y la factura de sus novelas. En este sentido, adquieren especial relevancia sus propias palabras al justificar, en carta al amigo José Antonio Donoso, la inclusión del episodio político de la revolución de 1851 en Martín Rivas: “...he tenido mis razones, y como son

15 Tengo conocimiento, hasta la fecha, de un solo ensayo que realiza una lectura de Martín Rivas valiéndose de algunas de las hipótesis de Girad. Se trata de "Martín Rivas: Violencia mimética y pensamiento utópico”, publicado por Edson Faúndez V., Fernando Ibáñez y María Luisa Martínez en Estudios Filológicos 54 (2014): 49-67. 
varias, te diré una: para llegar a la escena en que Leonor declara su amor a Martín, necesitaba de circunstancias muy solemnes, porque los coloqué intencionalmente a una gran distancia social desde el principio"(Blest Gana, Epistolario1 29). En otras palabras, el autor no justifica el procedimiento apoyado en las premisas del propio discurso programático de 1861 en defensa de la novela nacional, que ha sido tan ventilado para sostener las interpretaciones de su ficción. El hecho histórico no aparece allí únicamente para darle color local o para incorporar los eventos de la historia patria, sino que por una necesidad intrínseca del desarrollo del argumento y de la adecuación al punto de vista adoptado por el narrador con respecto al tratamiento de la materia ficcional. Es decir, el novelista estaba muy atento a lo que exigía su conciencia de artesano con relación a los vectores internos que debían ser moldeados dentro de una totalidad coherente, para que la forma se realizara según la recta razón, a partir de las pautas estéticas con las cuales comulgaba. Esta es una razón formal y estética que demuestra que Blest Gana no se limitó solo a atender a los imperativos de una concepción de la literatura como misión, vinculados a la necesidad histórica de servir de herramienta para la construcción de la nación moderna.

En el caso de estas siete novelas, las festividades o reuniones sociales abundan y no como meras descripciones de los usos de la época: las tertulias, los almuerzos, las ruedas de jugadores, las fiestas en el campo, las fiestas de gala en Santiago, los bailes, los llamados "picholeos" de las clases populares, las festividades religiosas, como el Corpus Christi en La venganza o la fiesta de San Juan en La flor de la higuera, los santorales, los rodeos, constituyen todos ellos ocasiones privilegiadas para dinamizar los motivos en juego dentro de la ficción. Son parte constitutiva de la estructuración artística del argumento. Se destacan en esas escenas características esenciales de los protagonistas, su vestuario es puesto en relieve y las actitudes son descritas con minuciosidad de pintor, a servicio del proceso caracterizador y del desarrollo temático. Es el reino del espectáculo que le otorga a la visión de los seres y al ambiente toda su potencia, haciendo alusión a la acertada formulación de Peter Brook, cuando aborda la importancia de las cosas y de los objetos en el universo del realismo decimonónico, en su Realist Vision. Las festividades son ocasiones en las cuales el fluir de los acontecimientos se detiene para que entonces la mirada sobre el mundo narrado realice movimientos circulares, dando la impresión de un tiempo simultáneo, el nuevo tiempo que la modernidad mundana introducía con fuerza a mediados del siglo XIX, en las costumbres sociales, encarnadas en los participantes de la historia. En El ideal de un 
calavera hay varios de estos momentos: "Mientras Cayetana y Sinforosa cantaban la vieja canción del cisne; mientras Abelardo Manríquez hablaba con Candelaria, el cuadro general que formaban los demás circundantes había tomado poco a poco muy diverso aspecto del que tenía al principiar el canto" (Blest Gana, El ideal 187). El adverbio de tiempo reiterado da la impresión de esa simultaneidad de acciones que ponen el tiempo en una marcha plural en varias direcciones.

Verificamos que son muchos más que Mariluán los libros olvidados. Eso implica tener que pensar de manera más amplia, y al mismo tiempo más detenida, en los motivos de ese descarte sistemático y rotundo de las piezas componentes de esta totalidad. Dicha reducción no obedece de ninguna manera a criterios puramente estéticos. Podríamos formular dos preguntas a este respecto: una, sobre las razones de esa recepción selectiva; y la otra, sobre cuál podría ser la espina dorsal, la línea de fuerza que organiza el todo y las partes.

Mi impresión es que esa aproximación parcial por parte de los críticos -tanto los de la tradición clásica, como los de la tradición moderna-, determinó una amputación lamentable, cuyos resultados fueron un empobrecimiento de la lectura, el consecuente debilitamiento de la figura del escritor y la reducción de su complejidad y de su valor como pionero dentro del proceso de formación de la novela chilena.

Es cierto que tomarlo por un defensor de la causa indígena o del feminismo serían errores análogos al de esa amputación, motivados por un anacronismo y un nuevo desvío de visión igualmente parcial. No hay que olvidar que el mismo Blest Gana que publicaba Mariluán en 1862, trababa una amistad epistolar con el ministro de la guerra en la época, Federico Errázuriz Zañartu quien “...no trepidó en aconsejar una guerra de exterminio” de los indígenas, conforme está registrado en el diario El Meteoro, de marzo de 1869. De igual forma, sería un error considerarlo un precursor del feminismo solo porque la heroína de La venganza ejecuta a los hombres que la cortejan, en represalia por la violencia a la cual fue sometida en el pasado. El arrepentimiento final de la protagonista, hacia el final de la novela, comprueba que son otros los móviles de su conducta, ligados al universo ideológico y cultural de su tiempo. 
El proyecto es, sin embargo, mucho más ambicioso de lo que la crítica ha querido ver. Se trata de un novelista que escribió por "manía", como él mismo insistió en más de una oportunidad, expresamente en sus crónicas y en sus cartas, o en las entrelíneas de sus narradores y a través de las palabras ambivalentes de sus personajes. Si es verdad que en parte -como no podría dejar de serlo en aquel tiempo- su obra se ajusta al objetivo mayor de la construcción de un proyecto de nación, también es necesario convenir que se dispara en direcciones muy distintas y muy distantes de ese objetivo unívoco. Ya se ha afirmado que su estilo no es limpio, que está repleto de imprecisiones (lo mismo se dijo de Balzac). Pero lo cierto es que la suma de sus libros es la muestra cabal de la obra de un artista sensible de su época, dado a la tarea de pintar el mundo y a los seres a su alrededor como él los percibía, dentro de los límites de su ideología y con innegable empeño narrativo.

\section{BIBLIOGRAFÍA}

Alone (seudónimo de Hernán Díaz Arrieta). Don Alberto Blest Gana. Biografía y crítica. Santiago: Nascimento, 1940.

“Crónica Literaria”. El Mercurio de 19 de julio de 1970.

Araya, Guillermo. "Historia y sociedad en la obra de Blest Gana". Revista de crítica latinoamericana. Centro de Estudios Literarios Antonio Cornejo Polar 14 (1981): 29-64.

“Alberto Blest Gana”. Historia de la literatura hispanoamericana. Tomo II. Coord. Luis Iñigo Madrigal. Madrid: Cátedra, 1993. 163-191

Ballard, John. "Mariluán: la novela olvidada del ciclo nacional de Alberto Blest Gana". Literatura Chilena, creación y crítica 18 (1981): 2-9.

Bersani, Leo. "O realismo e o medo do desejo".1975. Literatura e realidade. Coord. Todorov,

Z. Lisboa: Dom Quixote. 1984. 51-86.

Blest Gana, Alberto. "Lo de antes y lo de ahora". 1858. El jefe de la familia y otras páginas.

Coord. Silva Castro. Santiago: Zig-Zag, 1956.

"De los trabajos literarios en Chile". La Semana 11, junio de 1959.

"La literatura Chilena: algunas consideraciones sobre ella". 1861. Recuperado de:

http://www.anales.uchile.cl/index.php/ANUC/article/view/3177/3089.

La aritmética en el amor. 1860. Santiago: Zig-Zag, 1961.

El pago de las deudas.1861. Paris: Ch. Bouret, 1884.

La venganza.1862. Lavergne (TN): Libros Para Kindle, 2015.

Martín Rivas.1862. Caracas: Ayacucho, 1977.

Mariluán.1862. Santiago: LOM, 2005. 
El ideal de un calavera.1863. Santiago: Andrés Bello, 1999.

La flor de la higuera.1864. Santiago: Zig-Zag, 1953.

Los transplantados. 1904. Santiago: Andrés Bello, 1993.

Epistolario. Coord. José Miguel Barros Franco. Vol. 1 y 2. Santiago: FABG/

DIBAM, 2011.

Brook, Peter. Realist Vision. Yale: Yale Univ. Press, 2005.

Concha, Jaime. Prólogo a Martín Rivas. Caracas: Biblioteca Ayacucho, 1977. IX-XXXIX.

Leer a contraluz: estudios sobre narrativa chilena de Blest Gana a Varas y Bolaño.

Santiago: Universidad Alberto Hurtado, 2011.

"Identidad, costumbres y experiencia de la nación: tres novelas y un viajero". 2016: 1-18. (En prensa).

Donoso Rojas, Carlos. "El puesto de Iquique en tiempos de administración peruana". Historia (Santiago) 36 (2003): 123-158.

Gargarella, Roberto. "Le cycle tragique du libéralisme latino-américain (1810-1860)". Les

Cahiers ALHIM 11(2005): 39-54.

Girard, René. Mentira Romántica y Verdad novelesca. Barcelona: Anagrama, 1985.

Shakespeare. O teatro da inveja. 1990. Rio de Janeiro: É Realizações, 2010.

González Stephan, Beatriz. Historiografía literaria del liberalismo hispanoamericano del siglo XIX. Habana: Casa de las Américas, 1987.

Gotschlich, Guillermo. "Grotesco y tragicomedia en El ideal de un calavera". Revista Chilena de Literatura 29 (1987): 119-147.

Hosiasson, Laura Janina. “Contradicciones de un narrador: Martín Rivas”. Hispanismo 2002: Literatura Hispano-americana. Coord. Adrián Fanjul, Ana Cecilia Olmos y Mario M. González. Org. São Paulo: Humanitas, 2004, III. 240-245.

"Blest Gana, Martín y el calavera". Revista Chilena de Literatura 75 (2009): 259-269.

Lascar, Amado. "Mariluán y el problema de la inserción del mundo indígena al Estado Nacional”. Working Paper Seres 16, Ñuke Mapuforlaget (2003):1-43.

Latcham, Ricardo. "Blest Gana y la novela realista”.1958. Varia Lección. Comp. Pedro Lastra y Alfonso Calderón. Santiago: DIBAM, 2000. 105-122.

Levin, Harry. The gates of horn. A study of five french realists. New York: Oxford Univ. Press, 1963.

Luckács. Georg. Ensayos sobre el realismo. Buenos Aires: Siglo Veinte, 1965.

Poblete, Juan. Literatura chilena del siglo XIX: entre públicos lectores y figuras autoriales. Santiago: Cuarto Propio, 2003.

Poblete Varas, Hernán. Alberto Blest Gana y su obra. Santiago: Pehuén, 1995.

Prólogo a la edición de El ideal de un calavera. Santiago: Andrés Bello, 1999.

Praz, Mario. "La mujer fatal en el romanticismo". La carne, la muerte y el diablo en la literatura romántica.1939. Barcelona: El Acantilado, 1999. 347-516.

Rebolledo, Daniel y Alonso Machuca. La flor fe la higuera. Cortometraje, GRIP Films, 2010. 
Román-Lagunas, Jorge. "Bibliografía anotada de y sobre Alberto Blest Gana". Iberoamericana 112-113 (1980): 605-647.

Romero, José Luis. Situaciones e ideologías en Latinoamérica. México: Unam, 1981.

Silva Castro, Raúl, "Blest Gana y su novela Durante la reconquista. Revista Chilena de Historia y Geografia.81 (1934): 5-57.

Alberto Blest Gana: vida y obra (1930-1920). Santiago: Zig-Zag, 1955.

Sommer, Doris. "Something to celebrate: National Nuptial in Chile and Mexico". Foundational fictions. California: Univ. of California, 1993.

Schwarz, Roberto. "Dinheiro, memória, beleza (O pai Goriot)". A seréia e o desconfiado. 1963. Rio de Janeiro: Paz e Terra, 1981. 167-187.

Triviños, Gilberto. "Mariluán de Alberto Blest Gana: Panóptico, utopía, alteridad”. Atenea 490 (2004): 33-57. 